\title{
Recent Advances on Telematics Engineering
}

\author{
Ramón Agüero Calvo \\ Universidad de Cantabria \\ Avda. los Castros s/n, 39005 Santander, Cantabria \\ E-mail: ramon@tlmat.unican.es \\ María Magdalena Payeras Capellà, Guillem Femenias Nadal \\ Universitat de les Illes Balears \\ Crta. de Valldemossa, km 7,5, 07122 Palma, Illes Balears \\ E-mail: mpayeras@uib.es,guillem.femenias@uib.es
}

\author{
Jaime Lloret \\ Universidad Politécnica de Valencia \\ Camino de Vera, s/n, 46022, Valencia, Spain \\ E-mail: jlloret@dcom.upv.es
}

Received: March 15, 2016 Accepted: March 31, 2016

Published: March 31, 2016

DOI: 10.5296/npa.v8i1.9365

URL: http://dx.doi.org/10.5296/npa.v8i1.9365

\begin{abstract}
This Special Issue includes extended versions of selected papers from the XII Jornadas de Ingeniería Telemática (JITEL 2015), that took place in Palma, Spain, from October 14th to 16th, 2015. These papers underwent a rigorous review process, ensuring that they present enough new material so as to be considered original contributions while avoiding self-plagiarism.
\end{abstract}

Keywords: Telematics, Networking, JITEL 2015. 


\section{MlMacrothink}

\section{Introduction}

Our society is witnessing great advances in the information and communications technology (ICT) arena. Telematics engineering is deemed to play a central role in this progress, thus making the dissemination of the investigations carried out by the research groups of the area a must.

The Jornadas de Ingeniería Telemática (JITEL) were created as a forum for the exchange of knowledge among the researchers of the Telematics Engineering area. It was intended to promote relations between researchers and students working in any of the Telematics Engineering related fields and also to raise awareness and to share knowledge and advances of this important technology area in the daily life of citizens. After twelve editions, JITEL has consolidated as a propitious forum for having meetings, discussions and dissemination between the groups focused on teaching and research on issues related to the networks and telematics services. It serves as an event to exchange experiences and results. JITEL 2015 [1] also encompassed two satellite events: the fourth Jornadas de Innovación Educativa (JIE), which serve as a forum to discuss the tools, procedures, and educational approaches that have been implemented following the adoption of the European space of higher education, and the I Workshop QoS and QoE in multimedia communications (QQCM).

The 2015 edition, held in Palma de Mallorca, has been organized by the Telematics Engineering area at the Universitat de les Illes Balears and the Telematics Association (ATEL) [2]. This year, in parallel to the regular sessions, which are traditionally seen in various scientific congresses, we promoted more open activities, which stimulate the exchange of ideas between experienced and novel researchers, as well as the creation of links and points of contact between different groups or research teams. To this end, we invited reputable keynote speakers to trigger a debate of different research lines and ongoing projects.

The topics of interest addressed in JITEL 2015 consisted of contributions related to any of the areas related to telematics, such as:

- Next generation Internet and network architecture.

- $5 \mathrm{G}$ networks.

- Coding techniques.

- Management of networks and services.

- Cloud-based services and protocols.

- Design multilayer in fixed and mobile networks.

- Energy efficiency in communications networks.

- Resource management in mobile networks.

- The Internet of things.

- Vehicular networks.

- Models, analysis and traffic control.

- Platforms of experimentation.

- Communication protocols and algorithms.

- Pricing and costs in communications networks.

- Networks and cognitive techniques. 
- Wireless local and metropolitan area networks.

- Active and passive optical networks. Transmission and switching. Overlapping networks. Supported services.

- Security, cryptography, privacy, and anonymity in communications networks.

- Technologies and protocols in sensor networks.

- Software-Defined Networking.

- Network virtualization.

- Semantic Web and linked data.

- Big Data.

- Web 2.0 and social networks.

- Interactive multimedia services: VoIP, VoD, etc.

- Telematic services for the information society.

- Techniques of cooperation in the network and the services.

This special issue includes 7 selected papers from JITEL 2015. The papers were carefully revised by independent reviewers to ensure that the selected contributions contain original and high quality material to warrant its publication in this journal. On behalf of the organization committee, we want to express our sincere gratitude to all the sponsors and collaborators of the event, as well as to all the speakers, attendees, members of the committees and reviewers.

Two of the papers of the special issue are related to Hybrid Cloud. Cloud Computing offers on-demand storage and computational services to third parties and the hybrid cloud architectures offer a mix of the advantages of private and public clouds.

The FINESCE project is the smart energy use case project of the Future internet public private partnership programme. Both papers use FINESCE testbed to present their proposals. In [3], A. Briones et al. respond to the need of efficient resource allocation when various services have to be allocated in more than one cloud. The proposal tries to minimise the overall operating costs. The purpose of the paper is to define a methodology to assist in the selection of the cloud in the smart grid. The authors define a set of metrics and present a decision tree for the selection of the cloud. J Sánchez et Al. present in [4] a security evaluation the Hybrid cloud of FINESCE. Security and data privacy have to be taken into account not only for transit data but also for stored data or third party resources and organizations must analyse the threads and risks to which they will be exposed when moving information or applications to the cloud. The authors present a list of security requirements for hybrid cloud including the description of the problem and the level of priority. Moreover the paper exposes attacks and vulnerabilities related to cloud computing. The knowledge of these threads will be very useful in order to find countermeasures and reduce risks. A testbed platform has been used in order to simulate the distributed storage solution for FINESCE and the results of the security audit have been presented.

The European Railway Traffic Management System (ERTMS) is an initiative backed by the European Union to create a single Europe-wide standard for train control and command systems [5]. ERTMS consists of two basic components: the European Train Control System 
(ETCS), which is an automatic train protection system, and the GSM-R, a radio system designed to provide voice and data communication between the command centre and the train. These communication systems rely on the use of balises (also known as Eurobalises) situated along the railway track, which are energised and enabled to transmit only when the train antenna is above them, and on-board transmission systems consisting of the antenna unit and BTM (Balise Module Transmission) function. The Eurobalise-BTM communications suffer from interferences and perturbations due to the complex electromagnetical environment of the railway domain. The paper by Lara Rodriguez et al., entitled "Eurobalise-Train communication modelling to assess interferences in railway signalling systems," uses a general purpose simulation tool to model the Eurobalise-BTM communication flow. This model provides physical layer performance metrics such as the received power, signal-to-noise ratio and bit error rate, which have been validated using real measurements obtained in a laboratory testbed. The model presented in this paper is one of the components of a full ERMTS simulation framework allowing the analysis of the signalling system, safety and availability of the railway system.

Cranial deformations such as positional plagiocephaly, brachycephaly and scaphocephaly are the most common cause of abnormal asymmetrical head shape. Alterations of the cranial shape are typically associated with the application of external pressure to the growing infant head. The pressure is most often caused by long periods of time with the head resting in the same position. In cases where the cranial deformation is severe, a custom-molded helmet may be advised. The helmet applies pressure on the infant's skull to promote a higher degree of symmetry. The cranial shape will improve over time, with the total daily hours of usage being a key metric to predict the amount of correction, to improve the follow-up for each patient and even to estimate the duration of the treatment. The paper by Antoni Oller et al., entitled "Adherence to a treatment of cranial deformities with a sensorised brace device" [6], proposes the use of a sensorised orthopaedic helmet as a control system allowing the paediatric staff to access reliable and hassle-free information about the parental adherence to the prescribed treatment and correct placement of the orthopaedic device. The proposed system integrates pressure sensors into the helmet and the collected information is processed by a micro controller that is connected to a mobile device via Bluetooth. A mobile application is then responsible of sending the information to the cloud where it will be available to those people (relatives, caregivers, and doctors) involved in the treatment. The conclusion is that incorporating the adherence module would encourage parents and caregivers to be more constant, reducing in this way the duration of the treatment.

In [7], E. Molina et al. exploit the Software Defined Networking paradigm, and the OpenFlow protocol, to develop a protocol to establish redundant paths. The so-called Parallel Redundancy Protocol (PRP) is used to ensure reliability in critical industrial environments over wireless local area networks (WLAN) infrastructure. The use of OpenFlow, whose signalling is assumed to be transmitted out-of-band, eases the establishment of redundant paths. The paper uses a real implementation of the OpenFlow protocol, over an emulated platform, as well as simulation techniques, to assess the performance of the proposed solution, showing that it clearly outperforms legacy solutions, both in terms of throughput and packet 
loss rate.

J. Carmona-Murillo et al. present, in [8], a thorough analysis of the performance of two of the most relevant mobility management solutions for IP networks: Mobile IPv6 and Proxy Mobile IPv6. They first propose an analytical model of both the signalling overhead and the handover latency of both solutions. Afterwards, they use open source implementations of both protocols to carry out an experimental study of their performance, using a video streaming service over both UPD and TCP. They characterize both the throughput and the video quality (by means of the Peak Signal to Noise Ration, PSNR) using different configurations of the testbed, in terms of delay and packet loss rate. Although the used implementations are operational, the authors conclude that they still require some additional work to be used to offer real services.

In [9], M. García-Pineda et al. discuss how Factor Analysis techniques can be exploited to obtain objective quality metrics for video streaming services. The authors claim that the advent of Cloud Mobile Media Services leverages the need to improve current techniques to assess the quality of this type of services. They propose the use of several objective metrics to estimate the widespread subjective Mean Opinion Score (MOS) based on Factor Analysis techniques. They study the impact of including a larger number of variables, as well as the statistical moments that should be considered in order to guarantee a certain accuracy. A comparison with well-known video quality algorithms yield the good performance of the proposed techniques.

We hope that this special issue helps to provide a better understanding of the advances on the telematics engineering area. Concluding the editorial for this special issue, we would like to thank all the authors for their efforts in the elaboration of the papers, as well as the reviewers for their timely, comprehensive and constructive reviews.

\section{References}

[1] Jornadas de Ingeniería Telemática (JITEL), http://jitel15.uib.es/ [Last Access: March 30, 2016]

[2] Asociación de Telemática (ATEL), http://www.telematica.ws/ [Last Access: March 30, 2016]

[3] Alan Briones, Ramon Martin de Pozuelo, Joan Navarro, Agustín Zaballos, "Resource Allocation on a Hybrid Cloud for Smart Grids", Network Protocols and Algorithms, Vol. 8, Issue 1, pp. 7-25, 2016. http://dx.doi.org/10.5296/npa.v8i1.8721

[4] Julia Sánchez, Guiomar Corral, Ramon Martín de Pozuelo and Agustín Zaballos, "Security issues and threats that may affect the hybrid cloud of FINESCE", Network Protocols and Algorithms, Vol. 8, Issue 1, pp. 26-57, 2016. http://dx.doi.org/10.5296/npa.v8i1.8727

[5] Lara Rodriguez, Christian Pinedo, Igor Lopez, Marina Aguado, Jasone Astorga, Marivi Higuero, Iñigo Adin, Guillermo Bistué, Jaizki Mendizabal, “Eurobalise-Train communication modelling to assess interferences in railway control signalling systems”, 
Network Protocols and Algorithms, Vol. 8, Issue 1, pp. 58-72, 2016. http://dx.doi.org/10.5296/npa.v8i1.8731

[6] Antoni Oller, Jesús Alcober, Juan López, Guillem Tarín, Lucero Rosas and Julio García "Adherence to a treatment of cranial deformities with a sensorised brace device", Network Protocols and Algorithms, Vol. 8, Issue 1, pp. 73-91, 2016. http://dx.doi.org/10.5296/npa.v8i1.8732

[7] Elias Molina, Eduardo Jacob and Armando Astarloa, "Using OpenFlow to control redundant paths in wireless networks", Network Protocols and Algorithms, Vol. 8, Issue 1, pp. 92-104, 2016. http://dx.doi.org/10.5296/npa.v8i1.8730

[8] Javier Carmona-Murillo, David Cortés-Polo, Jesús Calle-Cancho, José-Luis González-Sánchez, Francisco-Javier Rodríguez-Pérez, “Analytical and Experimental Evaluation of Handovers in IPv6 Mobility Management Protocols”, Network Protocols and Algorithms, Vol. 8, Issue 1, pp. 105-126, 2016. http://dx.doi.org/10.5296/npa.v8i1.8725

[9] Miguel García-Pineda, Santiago Felici-Castel and Jaume Segura-García, “Using Factor Analysis Techniques to Find Out Objective Video Quality Metrics for Live Video Streaming over Cloud Mobile Media Services”, Network Protocols and Algorithms, Vol. 8, Issue 1, pp. 127-148, 2016. http://dx.doi.org/10.5296/npa.v8i1.8850

\section{Copyright Disclaimer}

Copyright reserved by the author(s).

This article is an open-access article distributed under the terms and conditions of the Creative Commons Attribution license (http://creativecommons.org/licenses/by/3.0/). 